\title{
Mechanical properties of a low-temperature-cured ceramic matrix composite
}

\author{
C.S. Shin *, J.B. Wang \\ Department of Mechanical Engineering, National Taiwan University, No. 1, Sect. 4, Roosevelt Road, Taipei, Taiwan
}

Received 20 August 1997; received in revised form 27 November 1997; accepted 18 March 1998

\begin{abstract}
An alumina matrix composite reinforced by $S$-glass woven fabric has been developed which can be cured at below $300^{\circ} \mathrm{C}$. The current work examines the flexural strength and fracture toughness of this composite in various directions relative to the fabric weaving direction at room temperature, 200 and $500^{\circ} \mathrm{C}$. It is found that the flexural strength decreases as the angle between the flexural axis and the reference weaving direction increases from 0 to $45^{\circ}$. The strength is not affected by raising the temperature to $200^{\circ} \mathrm{C}$ but decreases by $\sim 65 \%$ at $500^{\circ} \mathrm{C}$. Flexural strength is markedly higher when loading is parallel to the plane of the fabric than normal to it. At all three temperatures tested, the $0^{\circ}$ specimens have the highest fracture toughness; the toughness then drops in the $22.5^{\circ}$ specimens and rises slightly again in the $45^{\circ}$ specimens. Possible mechanisms leading to the observed phenomena are discussed. Preliminary room-temperature fatigue strength results are also reported. Results presented herein can form part of a design data base of mechanical properties for this composite. Besides, the current results also indicate the optimum orientations to be adopted in component design to derive better strength and toughness. Fatigue testing data suggest that structural integrity under cyclic loading can be tracked by monitoring appropriate material stiffness values. 1998 Elsevier Science S.A. All rights reserved.
\end{abstract}

Keywords: Ceramic matrix composites; Fibre reinforcement; Low-temperature curing

\section{Introduction}

Fibre-reinforced polymeric composites are light, stiff and strong and can be tough. However, they cannot normally be used at temperatures above $250^{\circ} \mathrm{C}$, because the polymeric matrix will soften [1]. On the other hand, ceramics have extremely high Young's modulus, hardness and wear resistance. In particular, their excellent creep and oxidation resistances enable ceramics to retain reasonable strength at temperatures far higher than those applicable to metals. Their extreme brittleness makes ceramics materials highly susceptible to small defects and seriously limits their application to structural components. This drawback can in part be offset by the addition of reinforcing fibres to form a ceramic matrix composite (CMC). CMCs have a working temperature higher than that attainable by metals. However, the cost of fabrication of CMCs is also higher and it is rather difficult for $\mathrm{CMCs}$ to be formed into complex shapes. For intermediate-temperature applications, the Chung Shan Institute of Science and Technology, Taiwan, has recently developed a

* Conesponding author. Tel.: +886-2-23622160; Fax: +886-2-23622160; E-mail: csshin@ccms.ntu.edu.tw series of composites which can be cured at a lower temperature and applied at temperatures far higher than those achievable by conventional polymeric matrix composites [2-4].

In the present work, the mechanical properties of a lowtemperature-cured ceramic matrix composite reinforced by a woven glass fabric have been investigated. The composite was prepared from woven fabric prepreg. This allows good flexibility in the fabrication process. Moreover, woven fabric reinforcement potentially renders better out-of-plane stiffness, strength, impact resistance and toughness than tape laminates $[5,6]$. This kind of reinforcement is essentially two dimensional. Accordingly, the mechanical properties may depend differently on the direction of the reinforcing fibres. The flexural strength and the fracture toughness in various directions relative to the fabric weaving direction at room temperature have been investigated in this work. Preliminary tests on higher-temperature properties and room-temperature fatigue properties have also been evaluated.

\section{Experimental}

The as-received CMC materials were in the form of 27 $\mathrm{cm} \times 27 \mathrm{~cm} \times 4 \mathrm{~mm}$ plates. Fabrication of the plate involved 
the preparation of its prepreg, which was made by preimpregnating an orthogonally woven S-glass fabric with a mixture of alumina and an aluminium phosphate binder. A plate was then formed by stacking up a number of prepregs to the desired thickness. The resulting plate was hot pressed and cured at $180^{\circ} \mathrm{C}$ for $4 \mathrm{~h}$, followed by a postcure at $280^{\circ} \mathrm{C}$ for another $2 \mathrm{~h} \mathrm{[4].} \mathrm{On} \mathrm{curing,} \mathrm{the} \mathrm{binder} \mathrm{precipitated} \mathrm{into} \mathrm{a}$ crosslinked polymeric structure. It was then infiltrated with Dow Corning DC2104 silicone laminating resin. The edges of the plates are parallel to the two orthogonal directions of the fibre in the fabric.

All the room-temperature tests were carried out on an MTS 810 servohydraulic machine using a four-point bending fixture. The nominal size of the flexural strength and fatigue specimens was $40 \mathrm{~mm} \times 3 \mathrm{~mm} \times 4 \mathrm{~mm}$. The size of the fracture toughness specimens was $38 \mathrm{~mm} \times 6 \mathrm{~mm} \times 4 \mathrm{~mm}$. Specimens were cut with a diamond-impregnated saw at $0^{\circ}, 22.5^{\circ}$ and $45^{\circ}$ to one of the plate edges. These different specimen orientations will be referred to as specimen directions.

The flexural strength test essentially followed the CNS 12701 standard [7]. The inner and outer spans for four-point bending were 10 and $30 \mathrm{~mm}$, respectively. To understand the effect of in-plane and out-of-plane loading on flexural strength, the transverse bending load has respectively been applied normal to the plane of the fabric (denoted as the $\mathrm{N}$ direction) and parallel to the plane of the fabric ( $P$ direction). These different modes of loading will be referred to as different loading directions. Flexural tests for each combination of specimen direction and loading direction were repeated on 10 specimens.

Fracture toughness tests were carried out under P-direction loading. A starter notch extending $30 \%$ of the specimen width was cut in every fracture toughness specimen with a 127 $\mathrm{mm} \times 0.4 \mathrm{~mm}$ diameter diamond saw. The notch tip is roughly circular, with a root radius $\sim 0.2 \mathrm{~mm}$. The above specimen sizes were chosen so as to be compatible with existing grips and the furnace for high-temperature tests. To guard against the existence of size effects, larger fracture toughness specimens ( $76 \mathrm{~mm} \times 14 \mathrm{~mm} \times 4 \mathrm{~mm}$ ) have also been tested. The notched toughness tests for each specimen size and orientation were repeated on five specimens.

Fatigue tests were carried out under P-direction loading using the same gripping fixture as the flexural tests. Sinusoidal loading of $20 \mathrm{~Hz}$ and a stress ratio (minimum load/ maximum load) of 0.1 have been employed. A test was discontinued if the specimen survived $10^{6}$ cycles of loading. The load versus load-line displacement data were recorded intermittently to allow the specimen stiffness variations over the loading history to be deduced.

Fracture toughness tests normally employed starter notches as cut by the saw. To evaluate possible conservative effect associated with blunt starter notches, fatigue pre-cracking has been employed in a limited number of $0^{\circ}$ specimens. Precracking was carried out under four-point bending with the starter notch facing a tensile load. The pre-cracking load was chosen to give a nominal fatigue life of $10^{5}$ cycles in the vicinity of the notch tip as follows: the cyclic stress for the required fatigue life was first estimated from the fatigue test results; the load to produce such a stress al a distance $0.4 \mathrm{~mm}$ (twice the notch root radius) ahead of the notch tip was then calculated using a notch stress distribution formula suggested in Ref. [8]. Since no macroscopic crack was normally observed after $10^{5}$ cycles, a considerably larger number of pre-cracking cycles have also been employed.

Tests under 200 and $500^{\circ} \mathrm{C}$ werc carricd out with an Instron screw-type machine equipped with a furnace. The specimens were preheated and kept at the testing temperature for $5 \mathrm{~min}$ before loading commenced to ensure a uniform temperature distribution within them. The number of tests carried out under these higher temperatures were limited due to the limited availability of material.

\section{Results and discussion}

\subsection{Flexural strength}

Fig. 1 shows the average flexural strength data together with the standard deviations for different specimen and loading directions. For the same specimen direction, the strength is lower when the applied loading is normal to the plane of woven fabric ( $\mathrm{N}$ direction) than parallel ( $\mathrm{P}$ direction) to it. If the loading direction is fixed, the flexural strength decreases as the angle between the specimen axis and the reference weaving direction increases. Fig. 2 compares the typical load versus load-point displacement behaviour under $\mathrm{P}$ - and $\mathrm{N}$ direction loading. Both load-displacement traces have a roughly equal initial linear stage. Following this, the slope of the load-displacement trace under $\mathrm{N}$-direction loading tends to decrease and lag behind that of the $\mathrm{P}$ direction. On reaching the maximum load, a considerable amount of deformation occurred under N-direction loading. During this period, the applied loading dropped gradually before final fracture took place. Under P-direction loading, the specimen reached a

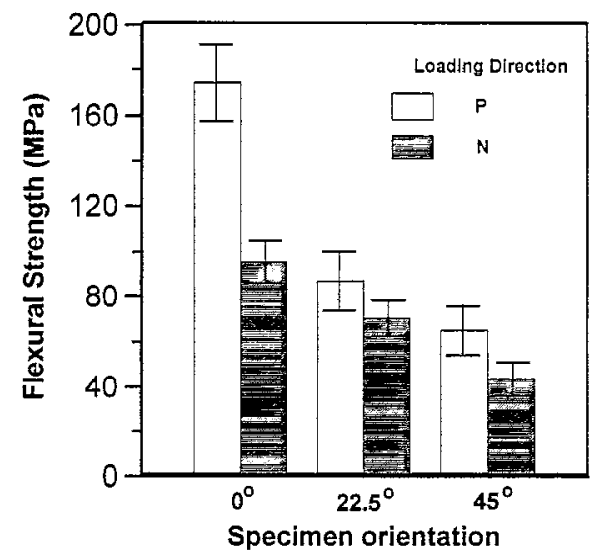

Fig. 1. Flexural strength for different specimen and loading directions at room temperature (error bars represent the standard deviations of the corresponding data) 


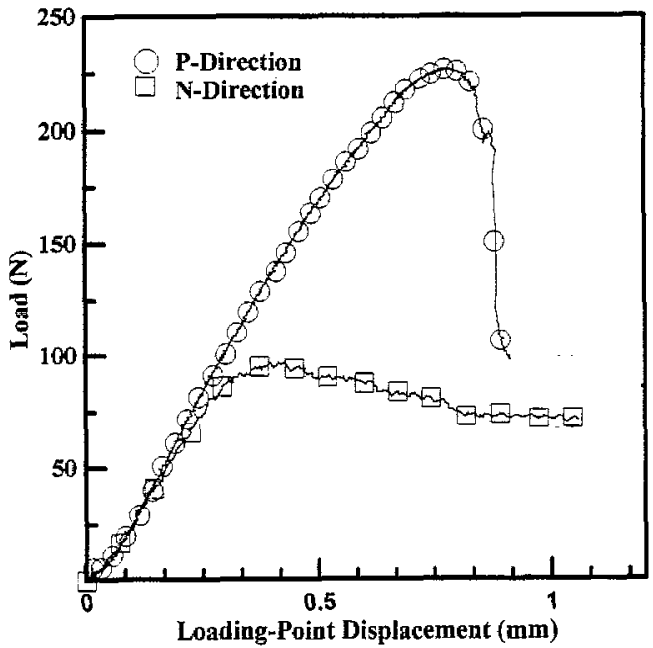

Fig. 2. Comparison of load vs. load-point displacement behaviour under $\mathrm{P}-$ and $\mathrm{N}$-direction loading.

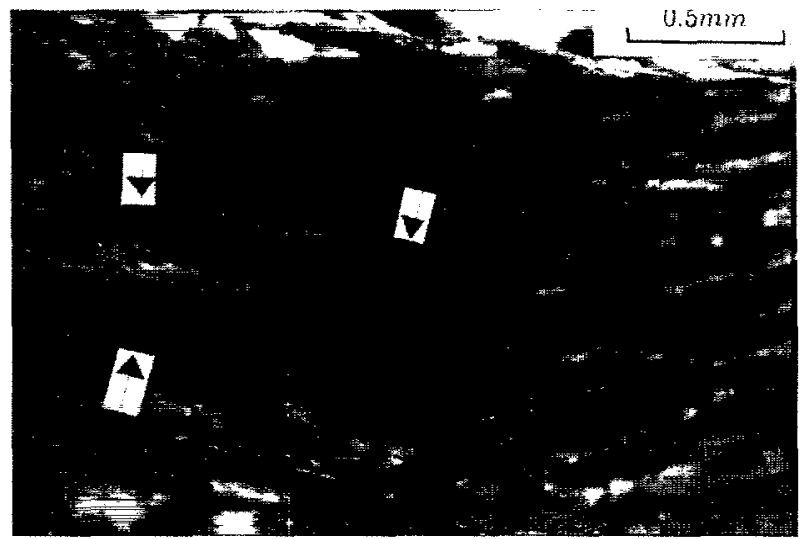

Fig. 3. Local delamination defects (arrows) in N-direction loaded specimen.

higher maximum load. The load then dropped abruptly on the occurrence of fracture.

Examining the sides of the $\mathrm{N}$-direction-loaded specimens revealed extensive local delamination voids (Fig. 3 ). In some layers these local voids joined up to produce the delamination of a complete layer. Under the same magnification, local delamination voids were not evident in the P-direction-loaded specimens. The latter typically failed by fracture into two segments and macroscopic damage appeared to be mainly in the vicinity of the fractured area.

Rief and Kromp [9] have explained the observed local delamination damage of laminated composites using a "stack model' based on the beam theory. Their explanation can be applied to the current case and is better expounded schematically by Fig. 4. Under the four-point bending configuration, classical beam-bending theory predicts that shear force will develop in the region between the inner and outer loading points. The plane of action of this shear force is parallel to the interface between the fabric and the matrix when the specimen is under $\mathrm{N}$-direction loading. If the interfacial bonding between fabric layers is weak and contains defects as shown, this shear force will favour the growth of interfacial

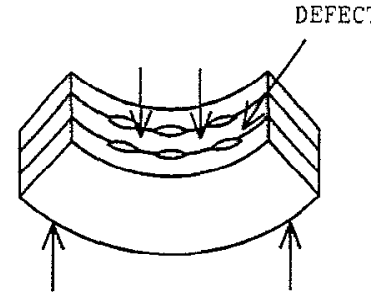

P DIRECTION LOADING

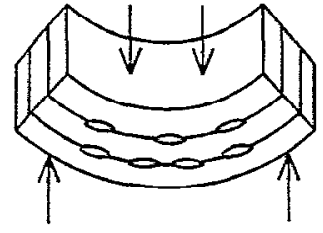

N DIRECTION LOADING
Fig. 4. Schematic comparison between the effect of different loading directions on incompletely bonded layers.

defects, leading to extensive local delamination voids. In the meantime, this shear force will also bring about localized relative sliding between the delaminated surface, giving rise to a considerable amount of bending deformation prior to complete fracture. As the degree of local delamination develops, the flexural rigidity of the specimen drops continuously. This gives rise to the phenomenon that the applied loading remains more or less steady while a large amount of deformation is occurring. In the P-direction-loaded specimens, the shear force is not acting on the interfacial planes and so little damage occurs until the specimen is near to fracture. This schematic comparison helps to explain the observed difference in flexural behaviour between the P- and N-directionloaded specimens.

A tentative explanation for flexural strength decreases as the specimen orientation angle increases runs as follows: for the $0^{\circ}$ specimens under bending, the tensile bending stress is parallel to yarns running along the specimen length direction. This stress is basically carried by yarns in this direction. As the specimen axis makes an angle with the reference weaving direction, the yarns are less efficient in carrying the applied stress. The brittle matrix is then subjected to a higher stress and is more susceptible to cracking. Once matrix cracking becomes widespread, the fibres are more prone to breakage. This phenomenon will be promoted by increasing the offaxis angle up to a maximum of $45^{\circ}$. This may explain the phenomenon of decreasing flexural strength when the specimen axis make an increasing angle with the reference weaving direction.

Figs. 5 and 6 present average flexural strength results with standard deviations at 200 and $500^{\circ} \mathrm{C}$ for some of the specimen orientations under $\mathrm{P}$ - and $\mathrm{N}$-direction loading. It can be seen that there is no deterioration in strength up to $200^{\circ} \mathrm{C}$. Serious strength degradation is evident at $500^{\circ} \mathrm{C}$. Even then, the material still possesses a strength of $60 \mathrm{MPa}$ at $0^{\circ}$ under P-direction loading.

Shin and Wang [10] reported the $0^{\circ}$ room-temperature flexural strength of the same material under $P$-direction loading without resin infiltration treatment as $113.1 \pm 9.8 \mathrm{MPa}$. Infiltration treatment raised the flexural strength by about $50 \%$.

The above results suggest that component design can make use of the optimum orientations to derive the best possible strength. Besides, for sample mechanical-property testing, 


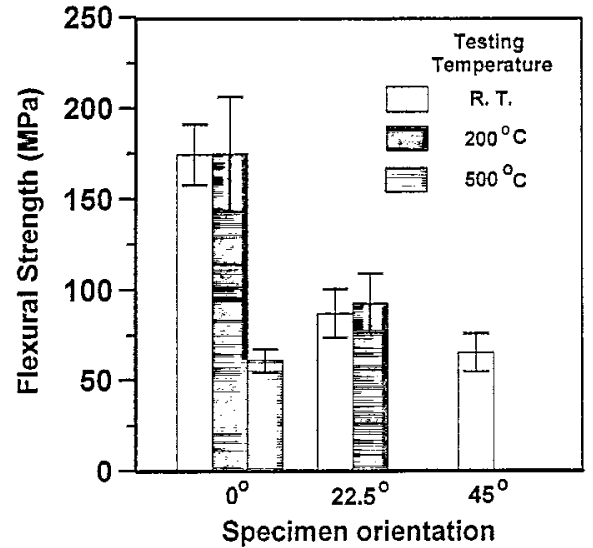

Fig. 5. Flexural strength for different specimen directions at different temperatures under P-direction loading (error bars represent the standard deviations of the corresponding data).

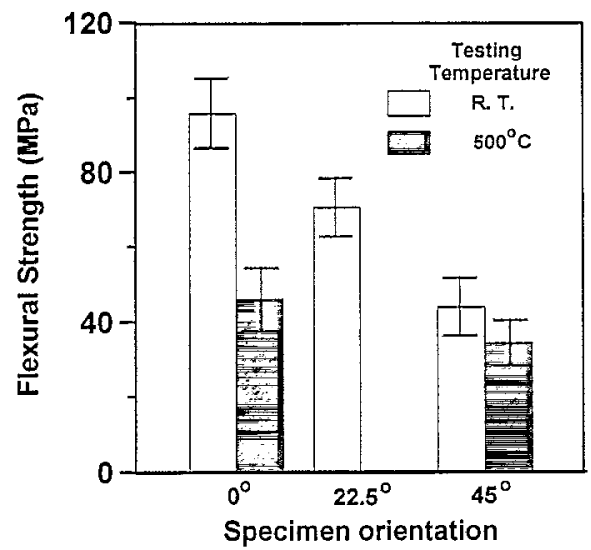

Fig. 6. Flexural strenght for different specinteri directions at different temperatures under $\mathrm{N}$-direction loading (error bars represent the standard deviations of the corresponding data).

one should be careful to simulate the correct specimen orientation and loading direction to get the correct result.

\subsection{Fracture toughness}

Fig. 7 shows the average and standard deviation of fracture toughness for the three specimen orientations at room temperature, 200 and $500^{\circ} \mathrm{C}$. At room temperature, the $0^{\circ}$ specimens have the highest toughness while the $22.5^{\circ}$ and $45^{\circ}$ specimens have roughly the same values. Room-temperature fracture toughness for the large $0^{\circ}$ specimens is the same as that for the corresponding small specimens and so a size effect did not occur with the current specimen dimensions. Raising the temperature to $200^{\circ} \mathrm{C}$ increased the scatter in toughness data. For the same specimen direction, the scatter range of the room-temperature toughness data overlapped and was even totally within that at $200^{\circ} \mathrm{C}$. On raising the testing temperature further to $500^{\circ} \mathrm{C}$, the fracture toughness in all three orientations dropped significantly.

Observation of the specimens during room-temperature testing showed that a damage zone ahead of the starter notch was seen instead of a clear macroscopic crack just before final

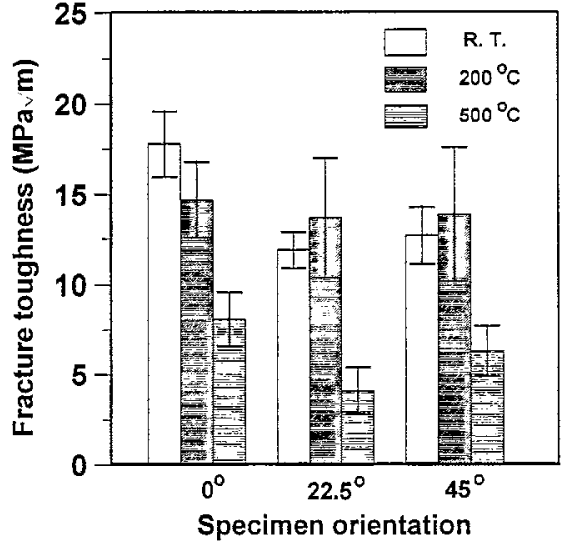

Fig. 7. Fracture toughness for different specimen directions at different temperatures under P-direction loading (error bars represent the standard deviations of the corresponding data)

fracture. Fig. 8 compares the typical room-temperature fractured specimens of the three different orientations. In each orientation, the overall fracture has a clear tendency to occur along one of the fibre directions (indicated by feathered arrows in Fig. 8). As a result, the major fracture directions make angles of $90^{\circ}, 67.5^{\circ}$ and $45^{\circ}$, respectively, with the specimen axis in the $0^{\circ}, 22.5^{\circ}$ and $45^{\circ}$ specimens. In the $22.5^{\circ}$ and $45^{\circ}$ specimens, the appearance of the pulled-out fibres (indicated by curved arrows in Fig. 8) suggested that the separation of specimens also occurred at an angle orthogonal to the predominant fracture directions (i.e., along the other fibre direction) in some layers of fabric. This tendency decreases as the testing temperature was raised. At $500^{\circ} \mathrm{C}$ the fracture appeared to be relatively more brittle in that a welldefined macroscopic crack was visible. The crack growth directions were also along one of the fibre directions and were quite uniform through the thickness in this case.

In fibre-reinforced composites, two important toughening mechanisms are crack bridging by fibres [11-15] and fibre pull-out [15-17]. In the former, unbroken fibres behind the crack tip restrain the opening of the crack. In the latter, fibre fracture occurs inside the matrix instead of on the plane of the matrix crack. Crack opening involves the pulling out of the broken fibre from the matrix and work must be done to overcome the frictional force between fibre and matrix. In woven fabric, additional friction occurs at the cross-over points between the warp and fill [18]. Both mechanisms reduce the crack driving force and thus increase the fracture toughness. Fig. 9(a) and (b) shows a typical fracture surface revealing the pulled-out fibres. From the action of fibre in the above two mechanisms, it is reasonable to deduce that given the same loading direction, the effectiveness of toughening will decrease as the fibres make an increasing angle with the specimen axis.

On the other hand, in a homogeneous isotropic material, it has been shown that under the same external loading, a mode I crack deflected from its perpendicular-to-load-axis direction will suffer a reduction in crack driving force [15,19-21]. The amount of reduction will increase with the degree of deflec- 

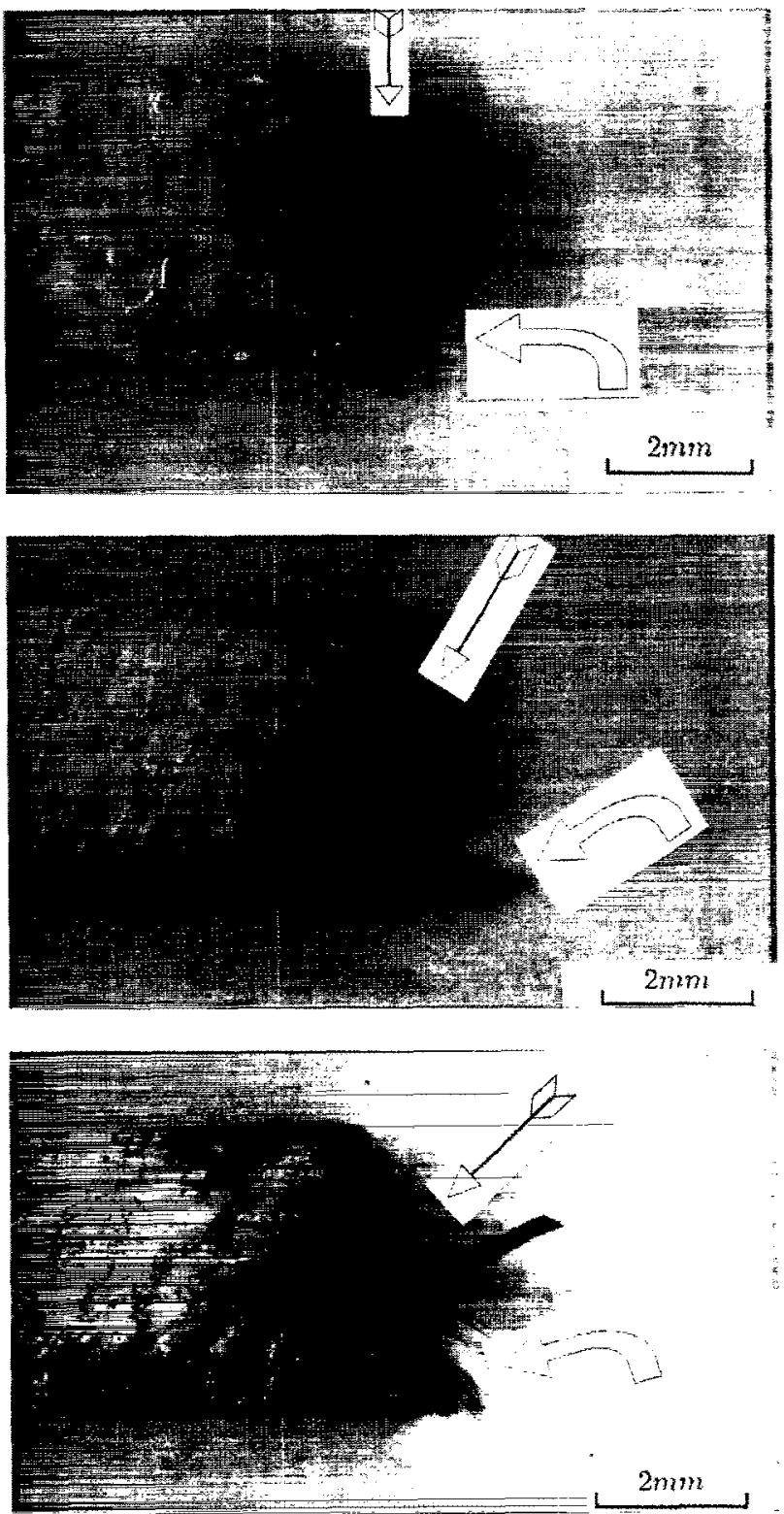

Fig. 8. Macroscopic views of the broken $0,22.5$ and $45^{\circ}$ fracture toughness specimens showing the respective fracture directions (feathered arrows) and pulled-out fibres (curved arrows indicate some pulled-out fibres in directions perpendicular to the fracture directions)

tion. In other words, a specimen with a deflected crack will appear tougher. The same effect is expected to exist in the current composite. As the crack has a tendency to grow along one of the fibre directions, the apparent toughness increase will be the highest in the $45^{\circ}$ specimens.

As a result, the toughening effects of fibre bridging/pullout and crack deffection have opposite trends for the differently oriented specimens. This may in part explain the observation that fracture toughness drops from $0^{\circ}$ specimens to $22.5^{\circ}$ specimens and then rises slightly but consistently in the $45^{\circ}$ specimens at all three temperatures tested. More work is needed to clarify the mechanisms that lead to toughness drop in the $0^{\circ}$ specimens but toughness rise in $22.5^{\circ}$ and $45^{\circ}$
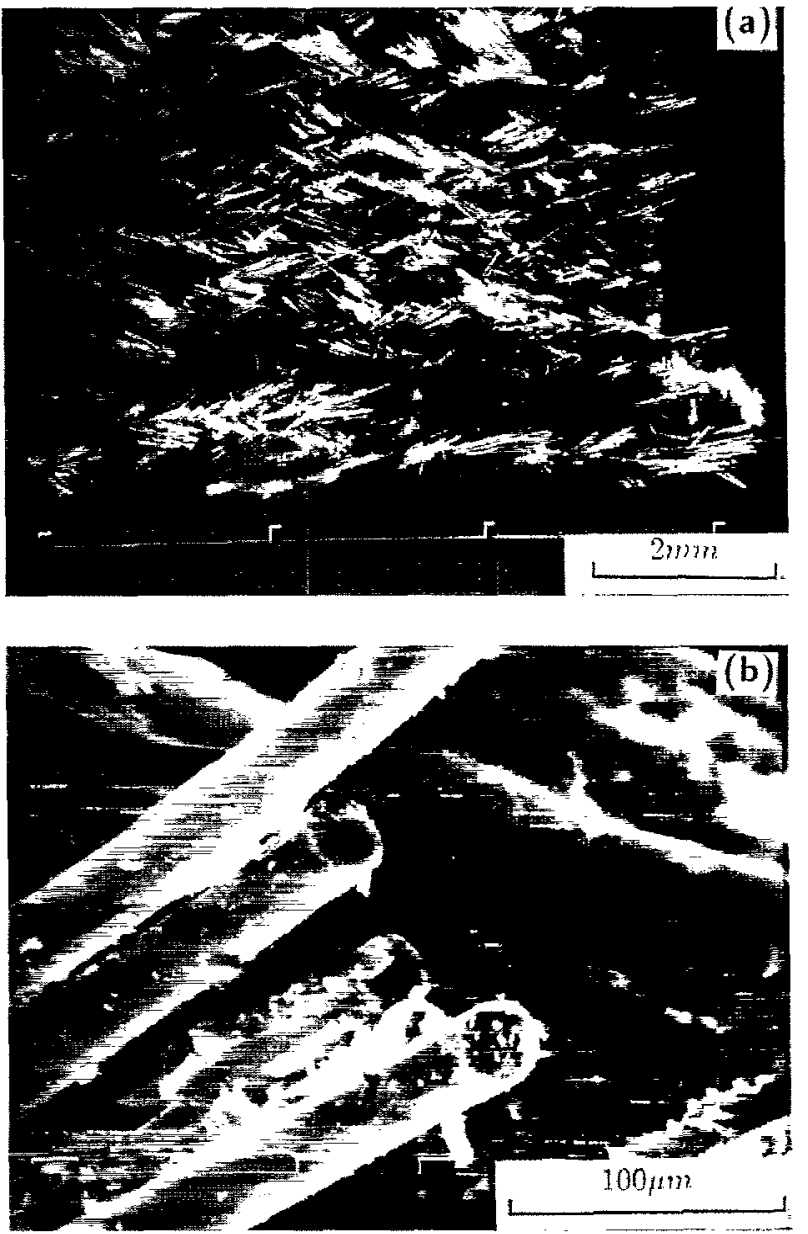

Fig. 9. (a) Low- and (b) high-magnification photographs of a typical fracture surface showing fibre pull-out.

specimens when the testing temperature changed from room temperature to $200^{\circ} \mathrm{C}$.

It is interesting to note that without the infiltration of silicone resin, the $0^{\circ}$ specimens have a room-temperature toughness of $8.5 \pm 0.6 \mathrm{MPa} \mathrm{m}^{1 / 2}$ [10], which is very close to that of the infiltrated $0^{\circ}$ specimen at $500^{\circ} \mathrm{C}$. Apparently the resin helps to bind the fibre to the matrix and increase the frictional resistance to fibre pull-out. At $500^{\circ} \mathrm{C}$, the resin may have vaporized or disintegrated and so the toughness value drops to that of the uninfiltrated case. It would be useful to carry out high-temperature tests for the uninfiltrated specimens to understand the contribution of resin infiltration better.

The above variation in toughness in different directions with testing temperature suggests that if a notch or a change in cross-sectional geometry has to be put into a component, the optimum direction in which this stress concentration should lie depends on the operating temperature.

The above fracture toughness tests were carried out on notched specimens. Several $0^{\circ}$ specimens pre-cracked by cyclic bending for different numbers of cycles have also been tested at room temperature. We expect the existence of a sharp crack will lower the measured toughness. 


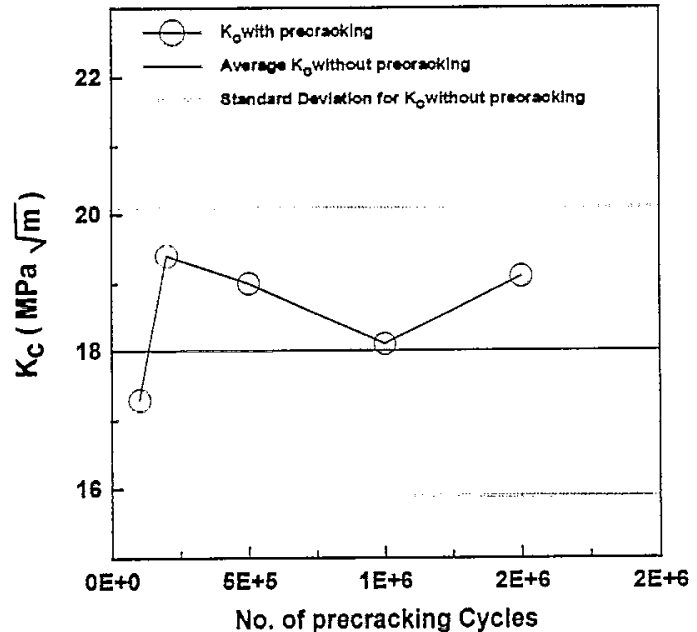

Fig. 10. Comparison of measured fracture toughness under different numbers of fatigue pre-cracking cycles.

Fig. 10 compares the fracture toughness of the pre-cracked specimens with that of the notched specimens. Although all the pre-cracked toughness values lie within the scatter band of the notched toughness values, all except the one undergoing 10000 pre-crack cycles have toughness values higher than the average notched toughness value. Close observation of the specimen undergoing 200000 cycles revealed a number of microcracks initiating from the notch tip (Fig. 11). Apparently, the increase in crack driving force due to the existence of a sharp crack is offset by the occurrence of multiple crack initiation $[15,22,23]$. Although cracks are not observed in all the pre-cracked specimen surfaces, it is reasoned that such multiple initiation may still have occurred at notch tip positions through the thickness, giving rise to the higher-than-average fracture toughness. For a small number of load reversals, such multiple initiation may not have fully developed and so the specimen undergoing 10000 loading cycles did not give an above-average toughness value.

\subsection{Fatigue strength}

The $S-N$ curve of the P-direction specimens is shown in Fig. 12. The fatigue strength is about $120 \mathrm{MPa}$. There is considerable scatter in data. It was observed that marked delamination failure occurred at an early stage in specimens with exceptionally low fatigue lives. Disregarding these delaminated specimens (square symbols in Fig. 12), the data fall into a more reasonable scatter band, the average of which may be described by

$\Delta \sigma=191.8 N^{-0.0303}$

where $\Delta \sigma$ is the stress range in $\mathrm{MPa}$ and $N$ is the number of cycles to failure.

One commonly used approach to quantify the degree of fatigue damage in fibre-reinforced composites employs the degradation of specimen stiffness [24-29]. This is reasonable, as in the course of fatigue damage, localized debonding,

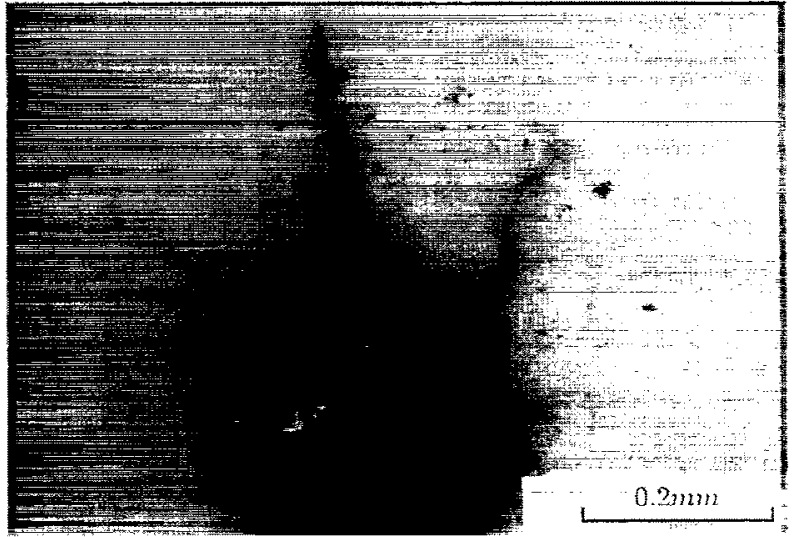

Fig. 11. Multiple crack initiation at notch tip under 200000 fatigue precracking cycles.

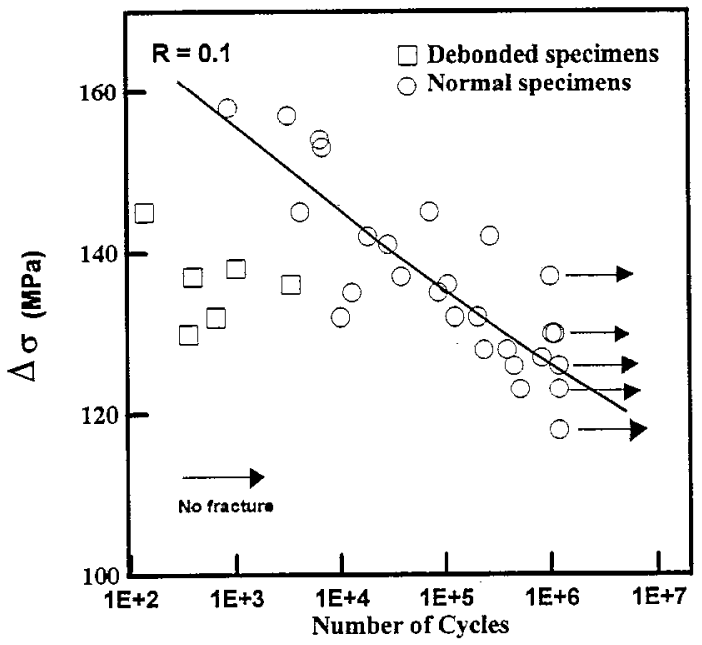

Fig. 12. Room-temperature $S-N$ curve for $0^{\circ}$ specimens under P-direction loading.

delamination, fibre breakage and matrix cracking will develop [30] and increase in extent. This will result in a gradual decrease in specimen stiffness. Specimen stiffness can be deduced from the load versus load-point displacement curve during fatigue testing. Hig. 13 shows part of the development of the load versus load-point displacement traces from a typical fatigue specimen. Two commonly used measures of stiffness are exemplified in this Figure. These include the initial elastic modulus (line BC in Fig. 13) [26] and the fatigue modulus (line OA in Fig. 13) [29].

In the current work, it was found that the loading rollers made dents in the specimens during the initial stage of cyclic loading. Roller indentations quickly became saturated after a few hundred loading cycles. The initial rapid changes in moduli associated with the development of these indentations were not relevant to the bulk fatigue damage. Moreover, in all the fatigue tests, it was observed that the initial elastic stiffness for any loading cycle (e.g., line BC in Fig. 13) was significantly lower than that observed at the remaining part of the cycle. This low initial stiffness may be attributed to the loose damaged material beneath the indentations and so does 


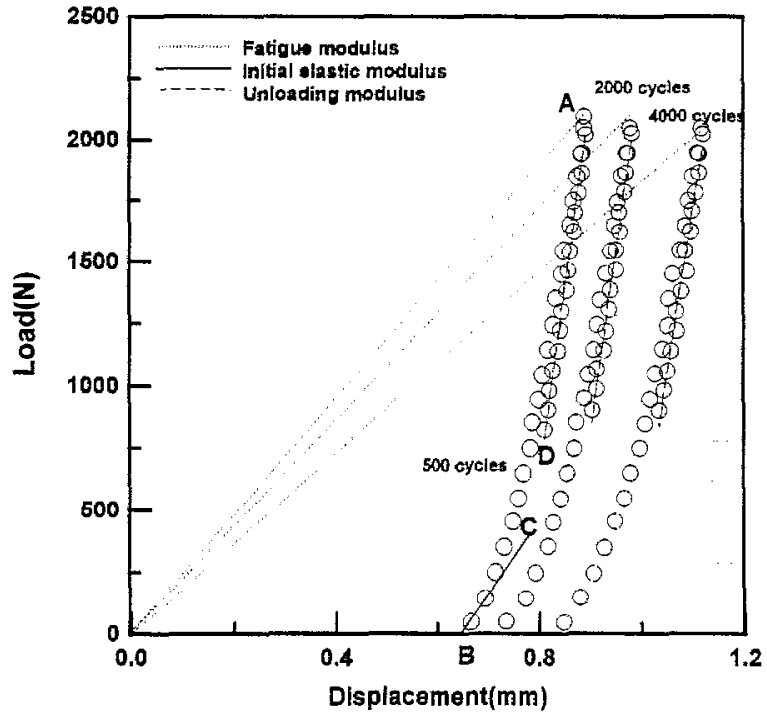

Fig. 13. Typical development of load vs. load-point displacement traces during fatigue testing showing the definition of fatigue modulus (line $0 \mathrm{~A}$ ), initial elastic stiffness (line $B C$ ) and unloading stiffness (line $A D$ ).

not represent the bulk stiffness of the specimens. For this reason, the unloading stiffness (line $\mathrm{AD}$ in Fig. 13) was monitored instead.

Figs. 14 and 15 show respectively the change in the fatigue modulus and the unloading modulus during fatigue tests for some specimens. Both moduli were normalized to the corresponding moduli at the thousandth loading cycle. The moduli at the first cycle were not used for normalization to avoid inaccuracy associated with the roller indentation phenomenon mentioned above.

The fatigue modulus decreases continuously as the cycle number increases (Fig. 14), while in the unloading modulus, ripples up and down are superimposed on an essentially downward trend (Fig. 15). Physically the fatigue modulus reflects the sum of cumulative specimen extension as well as the extension due to the current loading cycle, while the unloading modulus only reflects the latter. Instantaneous extension values due to the current cycle are subjected to some degree of scatter, giving rise to the ripples in Fig. 15. Conversely, the cumulative extension is far greater than the instantaneous one and so Fig. 14 is comparatively free from ripples.

If screening criteria for fatigue integrity of the specimens are to be chosen for these two moduli, a lower-bound normalized fatigue modulus of $0.85 \mathrm{can}$ be safely taken. This lower bound appears to be reasonable for the shorter-life cases $\left(<10^{5}\right.$ cycles), but may be too conservative for the long-life cases. On the other hand, a lower-bound normalized unloading modulus of 0.9 may be chosen as a fatigue integrity screening criterion. The conservative margin of this latter criterion is tight for the shortest-life specimen here but is reasonable for the other five cases. In particular, this screening criterion will not be overly conservative for the long-life specimens as is the case for fatigue modulus. This preliminary study suggests that structural integrity under cyclic loading

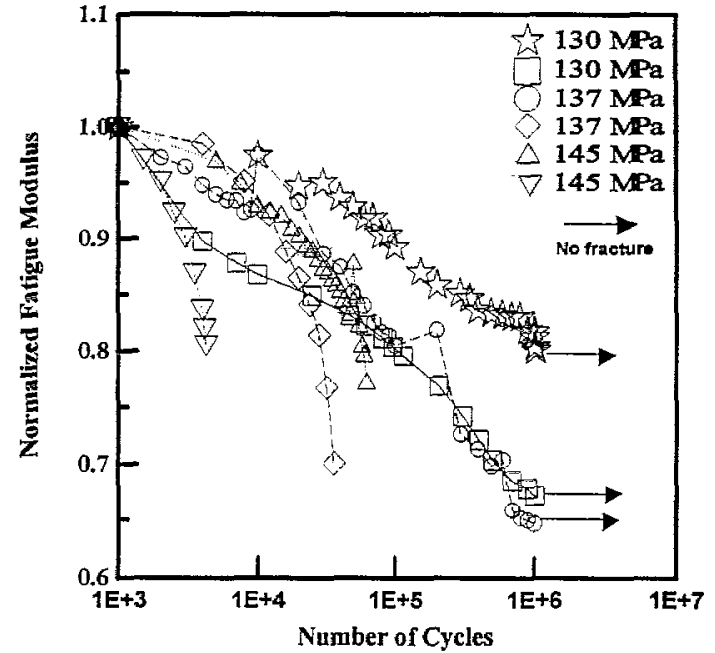

Fig. 14. Change in the fatigue modulus during fatigue tests.

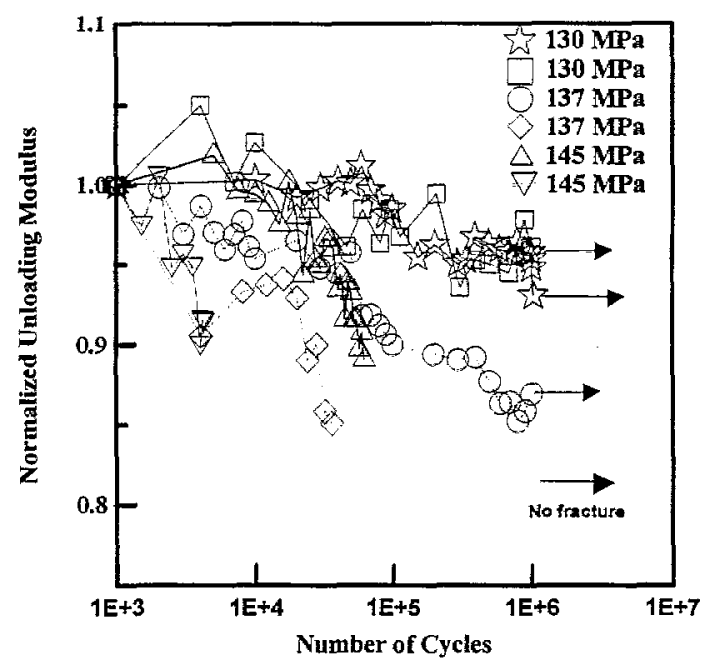

Fig. 15. Change in the unloading modulus during fatigue tests.

can be monitored if the stiffness change at a damage-prone region is tracked. This topic is worth more thorough investigation and verification on different specimen and component geometries.

\section{Conclusions}

The flexural strength, fracture toughness and fatigue properties of a low-temperature-cured glass-fabric-reinforced alumina composite has been investigated. A number of conclusions can be drawn:

(1) The flexural strength is higher when loading is applied parallel to the plane of fabric rather than normal to it. This may be explained by the different degrees of shear stress acting on interfacial defects under the two loading directions. Also, the flexural strength decreases as the angle between the specimen axis and the reference weaving direction increases from 0 to $45^{\circ}$. This suggests that component design can make use of the optimum orientations to derive better strength. 
Besides, sample mechanical-property testing should pay attention to employ the correct specimen orientation and to apply the relevant loading direction.

(2) The flexural strengths at $200^{\circ} \mathrm{C}$ are similar to that at room temperature. The material can still be used at $500^{\circ} \mathrm{C}$, at a reduced yet still usable flexural strength.

(3) At all three temperatures tested, the fracture toughness of the $0^{\circ}$ specimens is the highest; that of the $45^{\circ}$ specimens is slightly better than that of the $22.5^{\circ}$ specimens. The relative toughness magnitudes of the three specimen orientations change under different testing temperatures, suggesting the interaction of mechanisms which include fibre pull-out and crack deflection. These toughness results indicate that the optimum direction to put a stress concentration in a component depends on the operating temperature.

(4) The fracture toughness of pre-cracked specimens is higher than that of the notched specimens. This is attributable to multiple crack initiation in the former case.

(5) The fatigue strength under P-direction loading is about $120 \mathrm{MPa}$. Structural integrity under cyclic loading can be tracked and monitored using suitable bounding values for the fatigue modulus or unloading modulus. To this end, provision for measuring the material stiffness should be considered during the component design stage.

\section{Acknowledgements}

The authors are grateful to the Materials R\&D Center, CSIST, and in particular Dr C.C. Young and Mr Y.P. Hwang for providing the test material and other necessary aids to make this work possible.

\section{References}

[1] M.F. Ashby, Materials Selection in Mechanical Design, Pergamon Press, Oxford, UK, 1992.

[2] S.E. Hsu, J.C. Chen, J.F. Chang, B.J. Weng, D.G. Hwang, W.Y. Chen, High temperature organic and ceramic hybrid composite, Proc. National SAMPE Technical Conf., 1989, vol. 21, pp. 803-811.

[3] S.E. Hsu, H. Liu, C.H. Liu, J.C. Chen, D.G. Hwang, W.Y. Chen, C.I. Chen, J.F. Chang, High temperature behaviour of the innovation carbon/CSPI composite, Proc. National SAMPE Symp. and Exhibition, 1990, vol. 35, part 1, pp. 132-146.

[4] A phosphate based ceramic matrix composite and its fahrication, Taiwan Patent No. 162158 (1991).

[5] A. Kelly (Ed.), Concise Encyclopedia of Composite Materials, Pergamon Press, Oxford, UK, 1989.

[6] R.A. Naik, Failure analysis of woven and braided fabric reinforced composites, J. Composite Materials 29 (1995) 2334-2363.

[7] Standard testing procedures for measuring the flexural strength of engineering ceramics, CNS 12701, National Bureau of Standards, Taiwan, 1990.
[8] C.S. Shin, K.C. Man, C.M. Wang, A practical method to estimate the stress concentration factors of notches, Int. J. Fatigue 16 (1994) 242256.

[9] C. Rief, K. Kromp, A new model to describe the damage in a laminated carbon fibre reinforced carbon composite, in: A.M. Brandt, I.H. Marshall (Eds.), Brille Matrix Composites 2, Proc. 2nd Int. Symp, Britule Matrix Composites (BMC2), Cedzyna, Poland, 1988, pp. 108-117.

[10] C.S. Shin, Y.Y. Wang, Investigation on the mechanical properties of some toughened ceramics matrix composites, Tech. Report CS 84 0210-D-002-029, National Science Council, Taiwan, 1995.

[11] D.B. Marshall, B.N. Cox, A.G. Evans, The mechanics of matrix cracking in brittle-matrix fibre composites, Acta Metaliurgica 33 (1985) 2013-2021.

[12] D.B. Marshall, B.N. Cox, Tensile fracture of brittle matrix composites: influence of fiber strength, Acta Metallurgica 35 (1987) 2607-2619.

[13] M.D. Sensmeier, P.K. Wright, The effect of hbre bridging on fatigue crack growth in titanium matrix composites, in: P.K. Liaw, M.N. Gungor (Eds.), Fundamental Relationships between Microstructures and Mechanical Properties of Metal Matrix Composites. The Minerals, Metals and Materials Society, 1990, pp. 441-457.

[14] Y.C. Chiang, A.S.D. Wang, T.W. Chou, On matrix cracking in fiber reinforced ceramics, J. Mech. Phys. Solids 41 (1993) 1137-1154.

[15] R.O. Ritchie, Mechanisms of fatigue crack propagation in metals, ceramics and composites: role of erack tip shielding, Mater. Sci. Eng. A103 (1988) 15-28.

[16] A.G. Evans, R.M. McMeeking, On the toughening of ceramics by strong reinforcements, Acta Metallurgica 34 ( 1986) 2435-2441.

[17] P.F. Becher, C.H. Hsueh, P. Angelini, T.N. Tiegs, Toughening behaviour in fiber-reinforced ceramic matrix composites, J. Am. Ceram. Soc. 71 (1989) 1050-1061.

[18] N. Pan, Analysis of woven fabric strengths: prediction of fabric strength under uniaxial and biaxial extension, Comp. Sci. Technol. 56 (1996) $311-327$.

[19] S. Suresh, Micromechanisms of fatigue crack growth retardation following overloads, Engng. Fracture Mechanics 18 (1983) 577-593.

[20] K.T. Faber, A.G. Evans, Crack deflection process, Acta Metallurgica 31 (1983) 565-576.

[21] Y.C. Chiang, Crack deflection by rod-shaped inclusions, J. Mater. Sci. 27 (1992) 68-76

[22] A.G. Evans, Y. Fu, Some effects of microcracks on the mechanical properties of brittle solids, Acta Metallurgica 33 (1985) 15251531.

[23] T. Kishi, M. Enoki, Quantitative evaluation of microcracking in alloys and ceramics, in: K. Iida, A.J. McEvily (Eds.), Advanced Materials for Severe Service Application, Elsevier Applied Science, Amsterdam, 1987, pp. 61-76.

[24] H.T. Hahn, R.Y. Kim, Fatigue behavior of composite laminates, J. Composite Mater. 10 (1976) 156-180.

[25] T.K. O'Brien, K.L. Reifsnider, Fatigue damage evaluation through stiffness measurements in boron-epoxy laminates, J. Composite Mater. 15 (1981) 55-70.

[26] A. Poursatip, M.F.A. Ashby, P.W.R. Beaumont, The fatigue damage mechanics of a carbon fibre composice Ianninates: I - development of the model, Composites Sci. Technol. 25 (1986) 193-218.

[27] A. Poursatip, P.W.R. Beaumont, The fatigue damage mechanics of a carbon fibre composite laminates: II - life prediction, Composites Sci. Technol. 25 ( 1986) 283-299.

[28] W. Hwang, K.S. Han, Fatigue of composites - fatigue modulus concept and life prediction, J. Composite Mater. 20 (1986) 154-165.

[29] W. Hwang, K.S. Han, Fatigue of composites materials - damage model and life prediction, in: P.A. Lagace (Ed.), Composite Materials: Fatigue and Fracture, vol, 2, ASTM STP 1012, American Society for Testing and Materials, Philadelphia, 1989, pp. 87-102.

[30] R. Talreja, Fatigue of composite materials: damage mechanisms and fatigue life diagrams, Proc. Roy. Soc. London, Series A 378 (1981) $461-475$. 